\title{
PENGARUH PENDIDIKAN KESEHATAN TENTANG PERAWATAN TALI PUSAT TERHADAP PERILAKU IBU MERAWAT TALI PUSAT PADA BAYI
}

\author{
Nurwinda Saputri ${ }^{1 *}$, Miftakhur Rohmah ${ }^{2}$, Diny Vellyana ${ }^{3}$ \\ ${ }^{1}$ Prodi DIII Kebidanan, Fakultas Kesehatan, Universitas Muhammadiyah Pringsewu \\ 2 Prodi D-IV Kebidanan, Fakultas Keperawatan, IIK STRADA Indonesia \\ ${ }^{3}$ Prodi S1 Keperawatan, Fakultas Kesehatan, Universitas Muhammadiyah Pringsewu \\ Email :

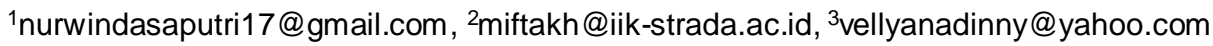

\begin{abstract}
ABSTRAK
Goals ke tiga dari tujuan Sustainable Development Goals (SDGS) adalah menciptakan derajat kesehatan yang baik ( sistem kesehatan Nasional) Pada 2030, mengakhiri kematian bayi dan balita yang dapat dicegah. Kematian anak di Indonesia terjadi pada masa baru lahir (neonatal), bulan pertama kehidupan yang banyak disebabkan oleh infeksi. Pada saat pemotongan tali pusat ketika bayi lahir maupun pada saat perawatannya sebelum puput (terlepasnya tali pusat) akan menyebabkan penyakit tetanus neonaturum. Promosi kesehatan merupakan proses meningkatkan kesehatan dan mensosialisasikan kepada masyarakat agar meningkatkan kesadaran, kemauan dan kemampuan serta pengembangan lingkungan yang dapat meningkatkan derajat kesehatan. Tujuan dari penelitian ini adalah mengetahui adanya Pengaruh Pendidikan Kesehatan Tentang Perawatan Tali Pusat Terhadap Perilaku ibu merawat tali Pusat pada bayi usia 1-7 hari. Metode : Penelitian ini adalah kuantitatif dengan desain penelitian analitik menggunakan metode quasi eksperiment dengan menggunakan rancangan one group pra-post test design pengetahuan ibu dan perilaku perawatan tali pusat. Subjek penelitian adalah seluruh bayi usia 1-7 hari. Hasil Penelitian : $p$ value : $0,000<0,05$, artinya ada Pengaruh Pendidikan Kesehatan Tentang Perawatan Tali Pusat Terhadap Perilaku ibu merawat tali Pusat pada bayi usia 1-7 hari.
\end{abstract}

Kata Kunci: Perawatan Tali Pusat, Pendidikan Kesehatan, Bayi 0-7 Hari

\section{PENDAHULUAN}

Goals ke tiga dari tujuan Sustainable Development Goals (SDGS) adalah menciptakan derajat kesehatan yang baik (sistem kesehatan Nasional) Pada 2030, mengakhiri kematian bayi dan balita yang dapat dicegah, dengan seluruh negara berusaha menurunkan Angka Kematian Neonatal setidaknya hingga 12 per $1.000 \mathrm{KH}$ dan Angka Kematian
Balita 25 per $1.000 \mathrm{KH}$.(Madolan, 2016) Infeksi postpartum akan tetap menjaddi penyebab utama morbiditas dan kematian neonatal diseluruh dunia, persentasi infeksi tertinggi berasal dari bakteri kolonisasi pada umbilicus karena perawatan yang berbeda-beda terkadang tradisi budaya dapat mempengaruhi perawatan pada tali pusat bayi.(Stewart et al., 2016)

\section{*Corresponding Author :}

Nurwinda Saputri

Prodi DIII Kebidanan, Fakultas Kesehatan

Universitas Muhammadiyah Pringsewu

Email : nurwindasaputri17@gmail.com 
Kematian anak di Indonesia terjadi pada masa baru lahir (neonatal), bulan pertama kehidupan. Seperti di Negara - negara berkembang kejadian ikterus pada bayi baru lahir (BBL) berkisar antara $50 \%$ pada bayi cukup bulan dan $75 \%$ pada bayi kurang bulan (Wiknjosastro, 2008). Estimasi Angka Kematian Bayi (AKB) di Provinsi Lampung dan Indonesia dari tahun 2000-2025 berdasarkan buku proyeksi penduduk Indonesia tahun 20002025, diperkirakan akan mengalami penurunan tingkat. Kematian bayi terjadi pada masa bayi perinatal (0-6 hari), diikuti kematian pada masa bayi neonatal ( $7-28$ hari) dan masa bayi (>28 hari $-<1$ tahun).

Penyebab kematian bayi perinatal Provinsi Lampung tahun 2015 disebabkan karena asfiksia sebesar $37,14 \%$ dan kematian neonatal terbesar disebabkan BBLR sebesar $28,18 \%$, sedangkan kematian bayi yang disebabkan karena infeksi sebesar 1,5\%.(Dinas Kesehatan Kota Bandar Lampung, 2015) Tetanus dan penyakit infeksi merupakan peyebab utama kematian bayi. Tetanus neonaturum (TN) dan infeksi tali pusat telah menjadi penyebab kesakitan dan kematian secara terus menerus di berbagai Negara. Setiap tahunnya sekutar 500.000 bayi meninggal karena tetanus neonaturum dan 460.000 meninggal akibat infeksi bakteri (Prawirohardjo, 2010) Angka kematian tetanus neonaturum yang dirawat di rumah sakit di Indonesia bervariasi dengan kisaran 10,8\% -
$55 \%$. Pada saat pemotongan tali pusat ketika bayi lahir maupun pada saat perawatan nya sebelum puput (terlepasnya tali pusat) akan menyebabkan penyakit tetanus neonaturum. Tali pusat itu sendiri adalah sebuah jaringan pengikat yang menghubungkan plasenta dengan fetus (janin). Fungsi dari tali pusat yaitu untuk menjaga kelangsungan hidup dan memberikan fasilitas untuk emrio dan janin berkembang.(Glyn O. Phillips, J. F. Kennedy, n.d.) Hal ini dapat terjadi karena perawatan yang kurang baik. Penyakit tetanus neonaturum yang terjadi pada neonatus (bayi berusia kurang dari 1 bulan) yang disebabkan karena Clastridium tetani, yaitu kuman yang mengeluarkan toksin (racun) dan menyerang system syarat pusat. Spora kuman tersebut masuk dalam tubuh bayi melalui pintu masuk satusatunya, yaitu tali pusat.(Saifudin, 2011) Sepsis neonatal adalah penyebab utama kematian ketiga bagi bayi di bulan pertama kehidupannya. Tali pusar yang baru saja dipotong dapat menjadi jalur bagi bakteri yang dapat menyebabkan sepsis dan kematian bayi baru lahir. (Coffey, P.S., Brown, 2017)

Pendidikan kesehatan adalah proses pemberian informasi kepada masyarakat agar dapat memecahkan masalah kesehatan yang dihadapi sehingga masyarakat lebih mandiri untuk menjaga kesehatannya. Perawatan tali pusat adalah perawatan pada tali pusat dengan menjaga agar luka tali pusat tetap bersih, tidak terkena air kencing,

\section{*Corresponding Author :}

Nurwinda Saputri

Prodi DIII Kebidanan, Fakultas Kesehatan

Universitas Muhammadiyah Pringsewu

Email : nurwindasaputri17@gmail.com 
kotoran bayi atau nanah. Bila kotor cuci tali pusat dengan air, keringkan dengan kain yang bersih dan kering. Hasil pra survey dari 6 orang ibu postpartum diperoleh $3(50 \%)$ orang ibu yang yang melakukan perawatan tali pusat dengan membubuhi tali pusat tersebut dengan kasa betadin, bubuk kunyit dan 1 orang ibu melakukan perawatan tali pusat dengan di bungkus daun siri dan garam dimana hal tersebut dapat menyebabkan infeksi pada tali pusat bayi. Sehingga pentingnya masyarkat mengetahui dan peduli akan kebersihan dan cara melakukan perawatan tali pusat pada bayi agar terhindar dari infeksi.

\section{METODE}

Jenis penelitian yang digunakan adalah penelitian kuantitatif. Rancangan penelitian bersifat Rancangan penelitian yang digunakan dalam penelitian ini adalah rancangan Quasi Eksperimen dengan rancangan One Group Pretest Post test. Dilakukan pada bulan Juli tahu 2019. Populasi dalam penelitian ini adalah seluruh ibu yang memiliki bayi usia 1-7 hari, Sampel yang akan diambil dengan cara accidental sampling. Variabel Independen Pendidikan Kesehatan dan Variabel terikat dalam penelitian ini adalah perilaku perawatan tali pusat.

\section{HASIL DAN PEMBAHASAN}

\section{Analisis Univariat}

Tabel. 4.1 Distribusi Rata-Rata Perilaku Perawatan Tali Pusat (Pre Test) Pada Bayi Usia 1-7 Hari

\begin{tabular}{lccccc}
\hline \multicolumn{1}{c}{ Variabel } & N & Mean & Min & Max & SD \\
\hline $\begin{array}{l}\text { Perilaku perawatan tali } \\
\text { pusat sebelum }\end{array}$ & 24 & 2,83 & 1,00 & 6,00 & 1,00 \\
$\begin{array}{l}\text { pendidikan kesehatan } \\
\text { (pre test) }\end{array}$ & & & & & \\
\hline
\end{tabular}

Dari hasil penelitian dapat dijelaskan bahwa sebelum dilakukan pendidikan kesehatan (pre-test), perilaku ibu dalam perawatan tali pusat rata-rata skor adalah 2,83 dengan standar deviasi 1,00 Nilai terkecil yaitu 1,00 dan nilai maksimum adalah 6,00. Perawatan tali pusat merupakan salah satu perawatan neonatus terutama pada dua minggu pertama kehidupan. Ibu harus menjaga tali pusat tetap bersih dan kering sampai akhirnya terlepas.

\section{*Corresponding Author :}

Nurwinda Saputri

Prodi DIII Kebidanan, Fakultas Kesehatan

Universitas Muhammadiyah Pringsewu

Email : nurwindasaputri17@gmail.com
(Prawirohardjo, 2010) Sudah banyak penelitian yang dilakukan untuk meneliti bahan yang digunakan dalam merawat tali pusat. Perawatan tali pusat secara medis menggunakan alkohol $70 \%$ atau bahan anti mikrobial seperti povidon-iodin 10\% (Betadin), klorheksidin, iodium tinstor dan lainlain yang tersebut sebagai cara modern. Sedangkan perawatan tali pusat metode tradisional mempergunakan madu, minyak ghee 
(India), atau kolostrum air susu ibu (Maryunani, 2008) (Saputri, 2019)

Hasil penelitian di atas sejalan dengan Penelitian oleh Rani Rahani yang berjudul Gambaran Pengetahuan lbu Nifas Tentang Perawatan Tali Pusat Di Desa Sukadamai Kecamatan Pulo Bandring Kabupaten Asahan Kisaran Tahun 2015, dengan hasil penelitian Dari 30 responden mayoritas ibu yang berpengetahuan cukup sebanyak 26 responden $(86,7 \%), \quad$ yang berpengetahuan kurang sebanyak 2 reponden $(6,7 \%)$ dan minoritas ibu berpengetahuan baik sebanyak 2 responden $(6,7 \%)$. Menurut asumsi peneliti ibu yang memiliki kesalahan dalam perawatan talipusat adalah ibu yang kurang memiliki pengetahuan tentang perawatan tali pusat sehingga untuk melakukan perawatan terhadap tali pusat itu tidak sesuai dengan standar kesehatan yang berlaku., dan pada penelitian ini terdapat responden dengan katagori primipara berjumlah 12 responden, sehingga mereka belum memiliki pengalaman dalam perawatan tali pusat.

\section{Tabel. 4.2 Distribusi Rata-Rata Perilaku Perawatan Tali Pusat (Post Test) Pada Bayi Usia 1-7 Hari}

\begin{tabular}{llllll}
\hline Variabel & N & $\begin{array}{l}\text { Mea } \\
\mathbf{n}\end{array}$ & Min & Max & SD \\
\hline $\begin{array}{l}\text { Perilaku perawatan tali pusat } \\
\text { sesudah pendidikan kesehatan } \\
\text { ( post test) }\end{array}$ & 24 & 6,33 & 4,00 & 8,00 & $1,55$. \\
\hline
\end{tabular}

Berdasarkan tabel 4.2 di atas, dapat dijelaskan bahwa sesudah dilakukan pendidikan kesehatan (post-test), perilaku ibu dalam perawatan tali pusat rata-rata skor adalah 6,33 dengan standar deviasi 1,55 Nilai terkecil yaitu 4,00 dan nilai maksimum adalah 8,00. Tujuan perawatan tali pusat adalah untuk mencegah terjadinya penyakit tetanus pada bayi baru lahir. Penyakit ini disebabkan karena masuknya spora kumantetanus kedalam tubuh melalui tali pusat, baik dari alat yang tidak steril, pemakaian obat-obatan, bubuk atau daun-daunan yang ditaburkan ke tali pusat sehingga dapat mengakibatkan infeksi. (Manuaba,
2011) Hasil penelitian ni sejalan dengan penelitian oleh Djawa, dkk, yang berjudul pengaruh penyuluhan tentang perawatan tali pusat terhadap kemampuan ibu post partum dalam perawatan Tali Pusat Bayi Baru Lahir (BBL) Di Bidan Swasta Tunggul Wulung. Hasil penelitian adalah Hasil penelitian membuktikan bahwa kemampuan ibu postpartum dalam perawatan tali pusat BBL sebelum penyuluhan, sebagian besar 15 orang $(75,0 \%)$ dikategorikan kurang baik, Kemampuan ibu postpartum dalam perawatan BBL sesudah penyuluhan, sebagian besar18 orang $(90,0 \%)$ dikategorikan baik. (Djawa et al., 2017)

\section{*Corresponding Author :}

Nurwinda Saputri

Prodi DIII Kebidanan, Fakultas Kesehatan

Universitas Muhammadiyah Pringsewu

Email : nurwindasaputri17@gmail.com 
Menurut asumsi peneliti perilaku perawatan tali pusat meningkat setelah diberikan pendidikan kesehatan hal ini terjadi karena keterpaparan informasi tentang perawatan tali pusat mampu mengubah perilaku ibu dalam melakukan perawatan tali pusat. Selain hal tersebut pendidikan kesehatan tentang tali pusat juga dengan mudah diserap oleh responden dikarenakan responden memiliki jenjang pendidikan dalam katagori pendidikan tinggi. seseorang yang memiliki pendidikan tinggi lebih mudah menerima dan memahami sesuatu yang diajarkan. Kemampuan ibu dalam perawatantalipusatsangat diperlukan untuk menjaga kondisi pusat bersih dan tidak terjadi infeksisertatali pusat pupus lebih cepat. Penyakit tetanus disebabkan karena masuknya spora kuman tetanus kedalam tubuh melalui talipusat,baik dar ialat yang tidak steril, pemakaian obat-obatan, bubuk atau daun-daunan yang ditaburkan ke tali pusat sehingga dapat mengakibatkan infeksi.

Tabel 4.3 Hasil Uji Normalitas Data

\begin{tabular}{lcccc}
\hline \multicolumn{1}{c}{ Variabel } & $\begin{array}{c}\text { Nilai } \\
\text { Skewness }\end{array}$ & $\begin{array}{c}\text { Standar } \\
\text { error }\end{array}$ & $\begin{array}{c}\text { Hasil } \\
\text { pembagian }\end{array}$ & $\begin{array}{c}\text { Simpula } \\
\mathbf{n}\end{array}$ \\
\hline $\begin{array}{l}\text { Perilaku perawatan tali } \\
\text { pusat pre test }\end{array}$ & 1,197 & 0,472 & 2,54 & $\begin{array}{c}\text { Tidak } \\
\text { normal }\end{array}$ \\
\hline $\begin{array}{l}\text { Perilaku perawatan tali } \\
\text { pusat post test }\end{array}$ & $-0,079$ & 0,472 & $-0,16$ & Normal \\
\hline
\end{tabular}

Tabel di atas menunjukkan hasil uji normalitas data, dimana diketahui variabel perilaku perawatan tali pusat saat pre testmenghasilkan nilai skewness yang dibagi dengan standar erornya adalah $>2$, sehingga dapat dijelaskan bahwa variabel tersebut tidak berdistribusi normal sedangkan variabel perilaku perawatan tali pusat saat post test menghasilkan nilai $<2$ yaitu berdistribusi normal. Untuk mengetahui Untuk mengetahui Pengaruh Pendidikan Kesehatan Tentang Perawatan Tali Pusat Terhadap Perilaku ibu merawat tali Pusat pada bayi usia 1-7 hari, dikarenakan salah satu variabel berdistribusi tidak normal maka uji yang digunakan adalah uji non parametric yaitu uji Wilcoxon test.

\section{Analisis Univariat}

Tabel 4.4 Pengaruh Pendidikan Kesehatan Tentang Perawatan Tali Pusat Terhadap Perilaku ibu merawat tali Pusat pada bayi usia 1-7 hari

\begin{tabular}{cccccc}
\hline Kelompok & N & $\begin{array}{c}\text { Mean } \\
\text { Rank }\end{array}$ & $\begin{array}{c}\text { Sum of } \\
\text { Rank }\end{array}$ & Z & $\begin{array}{c}\text { P- } \\
\text { Value }\end{array}$ \\
\hline
\end{tabular}

\section{*Corresponding Author :}

Nurwinda Saputri

Prodi DIII Kebidanan, Fakultas Kesehatan

Universitas Muhammadiyah Pringsewu

Email : nurwindasaputri17@gmail.com 


\begin{tabular}{llccccc}
\hline & & & & & & \\
\hline Perilaku & Negatif & 0 & 0,0 & 0,00 & $-4,304$ & 0,000 \\
\cline { 2 - 6 } $\begin{array}{l}\text { perawatan tali } \\
\text { pusat sebelum } \\
\text { dan sesudah }\end{array}$ & Positif ranks & 24 & 12,50 & 300,00 & \\
\cline { 2 - 5 } $\begin{array}{l}\text { pendidikan } \\
\text { kesehatan }\end{array}$ & Ties & 0 & & & \\
\hline
\end{tabular}

Dari tabel di atas dijelaskan bahwa hasil uji Wilcoxon signed ranks terdapat perubahan nilai sebelum dan sesudah diberikan intervensi. Positif ranks 24 dengan nilai $\mathrm{N} 24$ artinya terdapat 24 responden yang mengalami peningkatan skor nilai rata - rata. Negatif ranks 0 artinya tidak terdapat responden yang mengalami penurunan setelah pemberian intervensi. Mean ranks atau rata - rata peningkatannya sebesar 12,5 dan sum of ranks atau jumlah ranking positifnya sebesar 300. Berdasarkan hasil perhitungan Wilcoxon Signed Test maka nilai $z$ yang didapat sebesar4,304 dengan $p$ value 0,000 sehingga dapat disimpulkan bahwa ada pengaruh pendidikan kesehatan tentang perawatan tali pusat terhadap perilaku ibu merawat tali pusat pada bayi usia 1-7 hari.

Hasil uji Wilcoxon signed ranks terdapat perubahan nilai sebelum dan sesudah diberikan intervensi. Positif ranks 24 dengan nilai $\mathrm{N} 24$ artinya terdapat 24 responden yang mengalami peningkatan skor nilai rata - rata. Negatif ranks 0 artinya tidak terdapat responden yang mengalami penurunan setelah pemberian intervensi. Mean ranks atau rata - rata peningkatannya sebesar 12,5 dan sum of ranks atau jumlah ranking positifnya sebesar 300 . Berdasarkan hasil perhitungan Wilcoxon Signed

\section{*Corresponding Author :}

Nurwinda Saputri

Prodi DIII Kebidanan, Fakultas Kesehatan

Universitas Muhammadiyah Pringsewu

Email : nurwindasaputri17@gmail.com
Test maka nilai $\mathrm{z}$ yang didapat sebesar-4,304 dengan $p$ value 0,000 sehingga dapat disimpulkan bahwa ada pengaruh pendidikan kesehatan tentang perawatan tali pusat terhadap perilaku ibu merawat tali pusat pada bayi usia 1-7 hari. Pendidikan kesehatan adalah perilaku kesehatan, atau perilaku untuk memelihara dan meningkatkan kesehatan yang kondusif oleh sasaran dari promosi kesehatan. Pendidikan kesehatan dalam arti pendidikan. secara umum adalah segala upaya yang direncanakan untuk mempengaruhi oranglain,baik individu, kelompok, atau masyarakat, sehingga mereka melakukan apa yang diharapkan oleh pelaku pendidikan atau promosi kesehatan.(Notoatmodjo, 2012)

Hasil penelitian ini sejalan dengan penelitian oleh Meigia Yunita yang berjudul Pengaruh Pemberian Pengetahuan Terhadap Kemampuan Melakukan Perawatan Tali Pusat Pada Ibu Post Partum Primipara Di RSUD Wates Kulon Progo. Hasil penelitian ini adalah pemberian pengetahuan tentang perawatan tali pusat efektif dalam membantu meningkatkan kemampuan ibu post partum primipara dalam melakukan perawatan tali pusat bayi. Nilai yang diperoleh $p=0.005(p<0.05)$. (Yunita, Meiga, 2009) Berdasarkan pendapat peneliti setiap ibu pasti memiliki 
kemampuan untuk merawat tali pusat. Pada penelitian ini lebih banyak katagori ibu yang tidak bekerja sehingga dalam perawatan bayi baru lahir dilakukan sendiri. Informasi yang diberikan melalui pendidikan kesehatan mudah untuk diterima karena pada dasarnya kemampuan merupakan halyang telahada dalam dirikita sejak lahir. Kemampuan yang ada pada diri manusia disebut dengan potensi. Potensi yang ada pada manusia pada dasarnya bisa diasah.

\section{SIMPULAN}

Berdasarkan hasil penelitian dan uraian pada bab sebelumnya maka dapat diambil kesimpulan sebagai berikut, Distribusi rata - rata nilai perilaku ibu dalam perawatan tali pusat sebelum dilakukan pendidikan kesehatan (pre-test), adalah 2,83 dengan standar deviasi 1,00. Distribusi rata - rata nilai perilaku ibu dalam perawatan tali pusat sesudah dilakukan pendidikan kesehatan (post-test), adalah 6,33 dengan standar deviasi 1,55. Pengaruh Pendidikan Kesehatan Tentang Perawatan Tali Pusat Terhadap Perilaku ibu merawat tali Pusat pada bayi usia 1-7 hari. ( $p$ value : $0,000<$ 0,05 )

\section{DAFTAR PUSTAKA}

Coffey, P.S., Brown, S. C. (2017). Umbilical cord-care practices in low- and middle-income countries: a systematic review. MC Pregnancy Childbirth, 17, 68. https://doi.org/https://doi.org/10. 1186/s12884-017-1250-7

\section{Dinas Kesehatan Kota Bandar}

*Corresponding Author :

Nurwinda Saputri

Prodi DIII Kebidanan, Fakultas Kesehatan

Universitas Muhammadiyah Pringsewu

Email : nurwindasaputri17@gmail.com
Lampung. (2015). Profil

Kesehatan Kota Bandar Lampung.

Djawa, Y. D., Hariyanto, T., \& Ardiyani, V. M. (2017). PENGARUH PENYULUHAN TENTANG PERAWATAN TALI PUSAT TERHADAP KEMAMPUAN IBU POST PARTUM DALAM PERAWATAN TALI PUSAT BARI BARU LAHIR (BBL) DI PRAKTEK BIDAN SWASTA TUNGGUL WULUNG. Nursing News, 2, Nomor 2, 595606.

https://publikasi.unitri.ac.id/index .php/fikes/article/view/652/524

Glyn O. Phillips, J. F. Kennedy, P. A. W. (2002). (n.d.). Hyaluronan (J. F. K. G. O. P. P. A. W. V. C. Hascall (ed.); 1 ed.). Woodhead Publishing.

https://www.elsevier.com/books/ hyaluronan/kennedy/978-185573-570-5

Madolan, A. (2016). Persyaratan Rumah Sehat. www.mitrakesmas.com

Manuaba. (2011). IImu Kebidanan Penyakit Kandungan. EGC.

Maryunani, A. dan N. (2008). Buku Saku Asuhan Bayi Baru Lahir Normal (Asuhan Neonatal). Trans Info Media.

Notoatmodjo, S. 2012. (2012). Metodologi Penelitian Kesehatan. Rineka Cipta.

Prawirohardjo, S. (2010). Buku Acuan Nasional Pelayanan Kesehatan Maternal dan Neonatal. PT Bina Pustaka Sarwono Prawirohardjo.

Saifudin, A. B. (2011). Buku Panduan Praktis Pelayanan Kesehatan Maternal Neonatal. PT Bina Pustaka Sarwono Prawirohardjo.

Saputri, N. (2019). Modul Asuhan Neonatus, Bayi, Balita dan Anak Pra Sekolah. Pustaka Pranala.

Stewart, D., Benitz, W., Watterberg, K. 
L., Cummings, J. J., Benitz, W. E., Eichenwald, E. C., Poindexter, B. B., Stewart, D. L., Aucott, S. W., Goldsmith, J. P., Puopolo, K. M., Wang, K. S., Raju, T. N. K., Barfield, W. D., Keels, E. L., Lacaze, T., Mascola, M., \& Couto, J. R. (2016). Umbilical cord care in the newborn infant. Pediatrics, 138(3).

https://doi.org/10.1542/peds.201
6-2149

Wiknjosastro, H. (2008). IImu Kandungan (Edisi 2). EGC: Jakarta.

Yunita, Meiga, W. (2009). Pengaruh Pemberian Pengetahuan terhadap Kemampuan Melakukan Perawatan Tali Pusat Bayi pada lbu Post Partum Primipara di RSUD Wates Kulon Progo.

http://lib.unisayogya.ac.id/

*Corresponding Author :

Nurwinda Saputri

Prodi DIII Kebidanan, Fakultas Kesehatan

Universitas Muhammadiyah Pringsewu

Email : nurwindasaputri17@gmail.com 